\title{
Effects of an antimicrobial restriction system on appropriate carbapenem use in a hospital without infectious diseases consultation
}

This article was published in the following Dove Press journal: International Journal of General Medicine

\author{
Warangkhana Wanla' \\ Wasan Katip ${ }^{2,3}$ \\ Sakon Supakul ${ }^{2}$ \\ Porntipa Apiwatnakorn ${ }^{4}$ \\ Sompong Khamsarn' \\ 'Department of Pharmacy, Lamphun \\ Hospital, Lamphun, Thailand; \\ ${ }^{2}$ Department of Pharmaceutical \\ Care, Faculty of Pharmacy, Chiang \\ Mai University, Chiang Mai, Thailand; \\ ${ }^{3}$ Pharmaceutical Care Training Center \\ (PCTC), Faculty of Pharmacy, Chiang \\ Mai University, Chiang Mai, Thailand; \\ ${ }^{4}$ Department of Internal Medicine, \\ Lamphun Hospital, Thailand
}

Correspondence: Wasan Katip Department of Pharmaceutical Care, Faculty of Pharmacy, Chiang Mai University, 239, Suthep Road, Chiang Mai 50200, Thailand

Email wasankatip@gmail.com
Background: Gram-negative bacteria are becoming increasingly resistant to carbapenems and are related to the use of carbapenems. Thus, the main objective of this study was to compare the appropriateness of prescribing carbapenem before and after using an antimicrobial restriction system without infectious diseases consultation.

Materials and methods: A retrospective cross-sectional before and after study was conducted in Lamphun Hospital to limit the prescription of carbapenems. Data were obtained by a review of the medical records and electronic databases from the period September 2014 to January 2015 (before) and from September 2015 to January 2016 (after).

Results: A total of 360 antibacterial prescriptions were analyzed. The appropriateness of prescribing was higher after using the antimicrobial restriction $(55.0 \%)$ than before using the antimicrobial restriction system $(38.3 \% ; p=0.001)$. The amount of carbapenem in the defined daily dose per 1,000 bed days increased by $3.48 \%$ after using the antimicrobial restriction system when compared with before using the antimicrobial restriction system, which was not statistically significant $(p=0.611$ ). The incidence rates of nosocomial infections caused by resistance of Enterobacteriaceae to ertapenem before and after the intervention to limit antimicrobial therapy was found to have decreased from 4.80 to 0.95 infections per 1,000 patient days, respectively $(p=1.00)$. The expenditure for carbapenems in the average value of baht per patient was found to have decreased by $36.33 \%$ after using the antimicrobial restriction system when compared with before using the antimicrobial restriction system $(p=0.001)$.

Conclusion: These results suggest that antimicrobial restriction systems can increase the appropriateness of prescribing antibiotics. The expenditure for carbapenem was found to decrease after using the antimicrobial restriction system when compared with before using the antimicrobial restriction system, even without infectious diseases consultation. However, the amount of carbapenem in the defined daily dose per 1,000 bed days was not found to reduce after using the antimicrobial restriction system.

Keywords: antimicrobial restriction system, appropriate prescribing, carbapenem use, DDD

\section{Introduction}

Prevalence of resistance of gram-negative bacteria to multiple antibiotics has been reported worldwide. Especially, nosocomial infections such as Acinetobacter baumannii are becoming increasingly resistant to carbapenem. The number of occurrences of the same caused by the consumption of carbapenems has increased in hospitals. $^{1-3}$

Antimicrobial drugs worth over 10,000 million baht per year are being consumed in Thailand, leading to tremendous economic loss. The risk factors of developing 
antibiotic resistance are use of excessive and inappropriate antimicrobial therapy, including a lack of control measures. ${ }^{3,4}$

In 2014, it was found that resistance of A. baumannii to meropenem was quite high in Lamphun Hospital. Furthermore, consumption of meropenem is extremely costly, which can amount to drug bills worth $1,433,328$ baht. In addition, data regarding evaluation of appropriate prescribing of carbapenem in Lamphun Hospital from October 2013 to December 2013 indicated that there was $46.69 \%$ of inappropriate prescribing for most indications.

Antimicrobial drug stewardship includes formulary restrictions and preauthorization, prospective audit with intervention, and feedback. Thus, it has been the policy of Lamphun Hospital to use a restriction system for the carbapenem group. This policy was operated in September 2015. This restriction system controls the use of antimicrobial drugs in the wards as a process to solve the issue of antimicrobial resistance even when the hospital has no infectious diseases (ID) specialist. The antimicrobial drug controlling system used in a previous study found that it can both reduce and not reduce the consumption of antimicrobial drugs. ${ }^{5}$ However, using higher doses of the drug does not mean inappropriate use of the antimicrobial drug. Thus, there should be a process to evaluate the drug's reasonable dosage (drug use evaluation), coupled with an analysis of the antimicrobial consumption. Furthermore, there are limited studies on the antimicrobial drug controlling system in hospitals without ID consultation.

The main objective of this study was to compare the appropriateness of prescribing carbapenem before and after using antimicrobial restriction systems. Second, the study aimed to compare the amounts of antimicrobial drug in the form of prescribed dose per 1,000 bed days (defined daily dose [DDD]/1,000 bed days; DDD/1,000 a day), and the use of carbapenem in the average cost per patient baht (THB/ person) before and after using antimicrobial restriction systems in hospitals without ID specialists.

\section{Materials and methods Study design and patients}

This retrospective cross-sectional before and after study was conducted in Lamphun Hospital, a general hospital with 433 beds in the north of Thailand, to limit prescribing of carbapenem. This general hospital serves patients in Lamphun province and does not have an ID specialist service. Data were reviewed from the medical records and electronic databases of the period from September 2014 to January 2015 (before) and from September 2015 to January 2016 (after), thus began the control of antimicrobial drug use in September 2015 to assess the appropriateness of prescribing carbapenem, the amounts of antimicrobial drug in the form of prescribed dose per 1,000 bed days (DDD/1,000 bed days; DDD/1,000 a day) and the use of carbapenem in the average cost per patient baht (THB/person) before and after using an antimicrobial restriction system.

The patients were eligible for the study if they were older than 18 and received carbapenem from September 2014 to January 2015 (before) and from September 2015 to January 2016 (after). The patients were randomly selected using a simple random sampling technique. The two patient groups were selected from different time periods, during the period from September 2014 to January 2015 (before antimicrobial restriction, $\mathrm{n}=180$ ) and from September 2015 to January 2016 (after antimicrobial restriction, $\mathrm{n}=180$ ). The study findings were compared to the findings of the same period of the previous year that did not use any antimicrobial restriction system.

The Ethics Committee of Lamphun Hospital (LPN $51 / 2559$ ) approved this study with a waiver of informed consent, as nothing beyond routine diagnostic tests, monitoring, and treatment was performed during the study (minimal risk), obtaining informed consent was impracticable, and the collected data were stored anonymously.

\section{Process of prescribing of antimicrobial restriction system in Lamphun Hospital}

1. Specialty physicians prescribe the restricted antimicrobial agent initially for 3 days. They must fill in the requested antimicrobial use form and send it to the pharmacist unit, in order to restrict the dispensing of the antimicrobial drug to no more than 3 days within 24 h of the first prescription.

2. Pharmacists evaluate the antimicrobial use by taking into consideration the appropriateness of the indications, dosage, and route of administration, and adjust the dose based on the renal function. In case of inappropriate prescription, the pharmacist consults the physician for adjustment for appropriate use.

3. During the first 3 days of prescribing the antimicrobial drug, the internists who have been appointed by the administrator of the hospital assess the appropriateness of the antimicrobial use based on the indications, laboratory detection, and the patient's response to the treatment.

4. After that, the pharmacist dispenses the restricted antimicrobial agent according to the advice of the authorized physician who approved the drug. The pharmacist, then, follows up on the culture and the sensitivity of the bacteria to find out if the bacteria are resistant to the restricted antimicrobial agent or sensitive to the other narrow-spectrum antibiotics. Thereafter, the pharmacist consults the 
authorized physician who orders the empirical restricted antimicrobial agent to be adjusted in accordance with the susceptibility of the bacteria.

\section{Developed protocol for assessment}

Criteria for the appropriateness of carbapenem use have been developed by ID pharmacists, internists (internal medicine physicians) of Lamphun Hospital, and ID physicians. Also, they have been accredited by the Pharmacy and Therapeutic Committee of Lamphun Hospital.

\section{Outcome measures}

Comparison of the appropriateness of prescribing was carried out before and after using the antimicrobial restriction system. Prescribing is considered appropriate when it is able to meet all the criteria, which are as follows:

1. Appropriate for the indication: an empiric therapy/specific therapy is prescribed for the indications provided in the restricted antimicrobial use form, and the use of empiric therapy or specific therapy modified the treatment based on data obtained from the culture and the antimicrobial susceptibility test.

2. The appropriate dose for each patient based on the criteria defined by dose adjustment based on the patient's renal function.

Inappropriate prescribing is due to either of the following characteristics:

1. Inappropriate indication: an empiric therapy/specific therapy prescribed for which the indication criteria are not available in the restricted antimicrobial use form. In addition, the use of empiric therapy or specific therapy did not modify the treatment according to the data from the bacterial culture and the antimicrobial susceptibility test.

2. Inappropriate dose prescribing as specified in the assessment criteria. Or the dosage in patients with renal impairment was not adjusted.

The clinical response of treatment was defined by the following:

1. Complete response: resolution of fever, leukocytosis, and local signs and symptoms of infections at the end of treatment

2. Partial response: partial resolution of fever, leucocytosis, and local signs and symptoms of infections at the end of treatment

3. Failure: failure to meet all the criteria for clinical response
Empiric therapy: prescribed antibiotics against the most likely pathogens to account for those signs and symptoms of infection.

Specific therapy: the prescribed antibiotics subsequently amended when the responsible pathogen was identified and its susceptibility to antimicrobials was tested.

\section{Amount of antimicrobial drugs}

The study calculated the amount of drugs in the form of prescribed dose per 1,000 bed days (DDD/1,000 day bed; $\mathrm{DDD} / 1,000$ bed days), the average daily volume of drug use in the indications for adult patients without indicating the correct dose of the treatment but as a unit used in comparing consumption. The formula is as follows: ${ }^{6}$

$$
\begin{aligned}
& \operatorname{DDD}(\mathrm{g}) / 1,000 \text { day bed }= \\
& \frac{(\text { amount of drug used in unit grams }) \times 1,000}{\text { DDD }^{*} \times \text { number of day beds }}
\end{aligned}
$$

*DDD is defined by the World Health Organization (WHO) for each drug: meropenem, imipenem $=2 \mathrm{~g}$; ertapenem $=1 \mathrm{~g}$.

\section{Statistical methods}

Statistical analyses were performed using SPSS version 17. Comparison of appropriateness between prescribing before and after using the antimicrobial restriction system was performed using Fisher's exact test and chi-square test. Comparison of the amount of carbapenem in the dose prescribed per 1,000 bed days (DDD/1,000 patient days), infection per 1,000 patient days, including the use of carbapenem in the average cost per patient baht before and after using the antimicrobial restriction system, was carried out using independent $t$-test for parametric data or Mann-Whitney $U$ test for nonparametric data. All test results of statistical significance were two-sided, with the significance level set at 0.05 .

Multivariate analysis was performed to adjust some confounders when we compared the outcomes between before and after period groups.

\section{Results}

\section{Patient characteristics}

The total sample size was 360 prescriptions (before, $n=180$; after, $n=180$ ). The number of males was more than the number of females. Most of the patients were over 60 years of age, and the median of lengths of stay were 16 and 12 days for before and after groups, respectively (Table 1).

\section{Clinical data of patients}

From the total of 360 prescriptions, the clinical data regarding the underlying disease, the infection site, the type of 
Table I Patient characteristics

\begin{tabular}{|c|c|c|c|}
\hline \multirow[t]{2}{*}{ Characteristics } & \multicolumn{2}{|c|}{$\begin{array}{l}\text { Number of } \\
\text { prescriptions (\%) }\end{array}$} & \multirow[t]{2}{*}{$p$-value } \\
\hline & $\begin{array}{l}\text { Before } \\
(n=180)\end{array}$ & $\begin{array}{l}\text { After } \\
(n=180)\end{array}$ & \\
\hline \multicolumn{4}{|l|}{ Sex } \\
\hline Male & $108(60)$ & $116(64.4)$ & 0.384 \\
\hline Female & $72(40)$ & $64(35.6)$ & \\
\hline \multicolumn{4}{|l|}{ Age (years) } \\
\hline $18-30$ & $3(1.7)$ & $9(5)$ & 0.194 \\
\hline $31-60$ & $64(35.5)$ & $56(31.1)$ & \\
\hline$>60$ & $113(62.8)$ & $115(63.9)$ & \\
\hline $\begin{array}{l}\text { Length of stay, median } \\
\text { (min-max) }\end{array}$ & $16(1-122)$ & $12(1-161)$ & 0.001 \\
\hline \multicolumn{4}{|c|}{ Wards prescribing carbapenem } \\
\hline Medical ward & $150(83.3)$ & $169(93.9)$ & 0.001 \\
\hline Surgical ward & $21(11.7)$ & $3(1.7)$ & \\
\hline Orthopedic ward & $4(2.2)$ & $4(2.2)$ & \\
\hline Neurologic ward & $5(2.8)$ & $3(1.7)$ & \\
\hline Obstetric ward & $0(0)$ & $\mathrm{I}(0.6)$ & \\
\hline
\end{tabular}

Table 2 Clinical data of patients

\begin{tabular}{|c|c|c|c|}
\hline \multirow[t]{2}{*}{ Characteristics } & \multicolumn{2}{|c|}{$\begin{array}{l}\text { Number of } \\
\text { prescriptions (\%) }\end{array}$} & \multirow[t]{2}{*}{$p$-value } \\
\hline & $\begin{array}{l}\text { Before } \\
(n=180)\end{array}$ & $\begin{array}{l}\text { After } \\
(n=180)\end{array}$ & \\
\hline \multicolumn{4}{|l|}{ Underlying disease } \\
\hline Orthopedic disease & $4(4.12)$ & $2(2.67)$ & $<0.001$ \\
\hline Neurologic disease and CNS & $4(4.12)$ & $2(2.67)$ & \\
\hline Lower respiratory tract disease & II (II.34) & II (I4.66) & \\
\hline Other & $78(80.4 I)$ & $60(80.00)$ & \\
\hline \multicolumn{4}{|l|}{ Type of infection } \\
\hline Bone and joint infection & $4(2.20)$ & $2(1.10)$ & $<0.001$ \\
\hline Lower respiratory tract infection & $45(24.20)$ & $48(25.90)$ & \\
\hline Central nervous system infection & II (5.90) & $3(1.62)$ & \\
\hline Urinary tract infection & $53(28.60)$ & $49(26.49)$ & \\
\hline Sepsis & $20(10.70)$ & $36(19.45)$ & \\
\hline Bacteremia & $13(6.90)$ & $6(3.24)$ & \\
\hline Skin and soft tissue infection & $5(2.70)$ & $2(1.10)$ & \\
\hline Neutropenia & $0(0.00)$ & $2(1.10)$ & \\
\hline Intra-abdominal infection & $16(8.60)$ & $4(2.16)$ & \\
\hline Septic shock & $16(8.60)$ & $23(12.43)$ & \\
\hline Unknown & $3(1.60)$ & $10(5.4 I)$ & \\
\hline
\end{tabular}

Note: Other: cancer, liver disease, cardiovascular disease, renal disease.

Abbreviation: CNS, central nervous system. prescription, and the clinical outcome were analyzed. Investigation of data regarding before and after using the antimicrobial restriction system revealed that the most common types of infection were urinary tract infections, followed by lower respiratory tract infections (Table 2).

The type of prescribing and the clinical outcomes before and after the use of the antimicrobial restriction system are shown in Tables 2 and 3.

\section{Incidence rates of nosocomial infections due to resistant organisms}

The incidence rates of nosocomial infections caused by Enterobacteriaceae resistant to ertapenem before and after the intervention to limit antimicrobial therapy were 2.78 and 0.63 infections per 1,000 patient-days, respectively $(p=1.000)$. However, the incidence rates of nosocomial infections caused by Enterobacteriaceae resistant to meropenem were 2.02 and 0.32 infections per 1,000 patient days, respectively ( $p=1.000)$. The incidence rates of nosocomial infections caused by Enterobacteriaceae resistant to carbapenem (CRE) were 4.80 and 0.95 infections per 1,000 patient days, respectively $(p=1.000)$. The incidence rates of nosocomial infections caused by Pseudomonas aeruginosa resistant to meropenem were 3.53 and 1.28 infections per 1,000 patient days, respectively ( $p=1.000)$, as shown in Table 4.

\section{Appropriateness of prescribing}

Out of the total of 360 prescriptions, it was observed that the number of appropriate prescribing after using the antimicrobial restriction system was higher than the number before using the antimicrobial restriction system (Table 5). Inappropriate prescribing, including indication and improper dose, was found to have decreased after using the antimicrobial restriction system when compared with before using the antimicrobial restriction system (Table 6).

Table 3 Types of prescriptions and clinical outcomes

\begin{tabular}{|c|c|c|c|c|c|c|}
\hline \multirow[t]{2}{*}{ Parameter } & \multicolumn{2}{|c|}{ Number of prescriptions (\%) } & \multirow{2}{*}{$\begin{array}{l}\text { Unadjusted OR } \\
(95 \% \mathrm{CI})\end{array}$} & \multirow[t]{2}{*}{$p$-value } & \multirow{2}{*}{$\begin{array}{l}\text { Adjusted } O^{a} \\
(95 \% \mathrm{Cl})\end{array}$} & \multirow[t]{2}{*}{$p$-value } \\
\hline & Before $(n=180)$ & After $(n=180)$ & & & & \\
\hline Type of prescription & & & $2.162(1.417-3.300)$ & 0.000 & $2.329(1.425-3.805)$ & 0.001 \\
\hline Empiric therapy & $81(45.00)$ & $117(65.00)$ & & & & \\
\hline Specific therapy & $99(55.00)$ & $63(35.00)$ & & & & \\
\hline Clinical outcome & & & $0.575(0.178-0.973)$ & 0.005 & $0.594(0.153-1.036)$ & 0.008 \\
\hline Complete response & $0(0.00)$ & $46(25.60)$ & & & & \\
\hline Partial response & $90(50.00)$ & $49(27.20)$ & & & & \\
\hline Failure & $90(50.00)$ & $85(47.20)$ & & & & \\
\hline
\end{tabular}

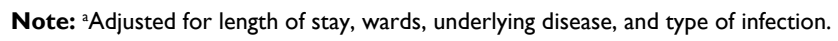
Abbreviations: $\mathrm{Cl}$, confidence interval; OR, odds ratio. 


\section{Amount of carbapenem used in dose}

In all of the 360 prescriptions, as regards the amount of carbapenem in the dose prescribed per 1,000 bed days after using the antimicrobial restriction system, it was found that the amount of meropenem had increased by $7.54 \%$ after the use of the antimicrobial restriction system when compared with before the use of the antimicrobial restriction system, but it was not statistically significant (Table 7). The utilization of ertapenem had decreased by $20.05 \%$ after using the antimicrobial restriction system when compared with before using the antimicrobial restriction system, but it was not statistically significant (Table 7).

\section{Expense for carbapenem}

In all of the 360 prescriptions, the expense for carbapenem in the average value of baht per patient (THB/person) was found to have significantly decreased (36.33\%) after the

Table 4 Incidence rates of nosocomial infections caused by resistant organisms before and after using the antimicrobial restriction system

\begin{tabular}{|c|c|c|c|}
\hline \multirow[t]{2}{*}{ Microorganism } & \multicolumn{2}{|c|}{$\begin{array}{l}\text { Number of } \\
\text { infections per } \\
\text { I,000 patient } \\
\text { days }\end{array}$} & \multirow[t]{2}{*}{$p$-value } \\
\hline & Before & After & \\
\hline \multicolumn{4}{|l|}{ Enterobacteriaceae } \\
\hline Ertapenem (R) Enterobacteriaceae & 2.78 & 0.63 & 1.000 \\
\hline Meropenem (R) Enterobacteriaceae & 2.02 & 0.32 & 1.000 \\
\hline CRE & 4.80 & 0.95 & 1.000 \\
\hline \multicolumn{4}{|l|}{ Pseudomonas aeruginosa } \\
\hline Meropenem (R) P. aeruginosa & 3.53 & 1.28 & 1.000 \\
\hline
\end{tabular}

Notes: Before: 3,96I patient days. After: 3,I32 patient days.

Abbreviations: CRE, Carbapenem (R) Enterobacteriaceae; $R$, resistant. use of the antimicrobial restriction system when compared with before the use of the antimicrobial restriction system ( $p=0.001)$. The values of meropenem and ertapenem were found to have significantly decreased by $30.01 \%$ and $53.90 \%$, respectively, after using the antimicrobial restriction system when compared with their values before using the antimicrobial restriction system (Table 8).

\section{Discussion}

Prolonged use of broad-spectrum antimicrobial agents can lead to increase in the risk of resistant bacteria (colonization of antibiotic-resistant bacteria) and repeated incidents of infections with resistant strains (secondary infection by antibiotic-resistant bacteria); the spread of resistant bacteria in hospitals and across wards in hospitals, and subsequent consumption of antimicrobial agents, has increased. So, when information regarding the pathogen and the susceptibility test of the bacteria is available, the specific antimicrobial effect on the pathogen, or the narrow-spectrum antimicrobial drug, based on the susceptibility test, should be put to use. Moreover, dosage, duration of antimicrobial treatment, and antimicrobial tissue concentration should be appropriate according to the antibiotic stewardship program. ${ }^{3}$

Despite the hospital chosen in this study not having ID consultation, the results show that an antimicrobial restriction system can increase the appropriateness of prescribing antibiotics. The expenditure for carbapenem was found to have decreased after using the antimicrobial restriction system when compared with before using the antimicrobial restriction system. In addition, the incidence rates of nosocomial infections caused by resistant organisms such as CRE and meropenem-resistant $P$. aeruginosa tended to decrease

Table 5 Appropriateness of prescribing

\begin{tabular}{|c|c|c|c|c|c|c|}
\hline \multirow[t]{2}{*}{ Parameter } & \multicolumn{2}{|c|}{ Number of prescriptions (\%) } & \multirow{2}{*}{$\begin{array}{l}\text { Unadjusted OR } \\
(95 \% \mathrm{Cl})\end{array}$} & \multirow[t]{2}{*}{$p$-value } & \multirow{2}{*}{$\begin{array}{l}\text { Adjusted } O^{a} \\
(95 \% \mathrm{Cl})\end{array}$} & \multirow[t]{2}{*}{$p$-value } \\
\hline & Before $(n=180)$ & After $(n=180)$ & & & & \\
\hline Appropriateness of prescribing & & & $1.966(1.292-2.993)$ & 0.002 & $2.150(1.35 \mathrm{I}-3.423)$ & $0.00 \mathrm{I}$ \\
\hline Appropriate & $69(38.3)$ & $99(55.0)$ & & & & \\
\hline Inappropriate & III (6I.7) & $81(45.0)$ & & & & \\
\hline
\end{tabular}

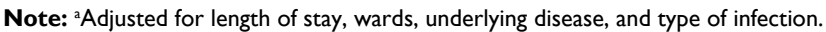

Abbreviations: $\mathrm{Cl}$, confidence interval; $\mathrm{OR}$, odds ratio.

Table 6 Inappropriate prescribing

\begin{tabular}{|c|c|c|c|c|c|c|}
\hline \multirow{2}{*}{$\begin{array}{l}\text { Inappropriate } \\
\text { prescribing }\end{array}$} & \multicolumn{2}{|c|}{ Number of prescriptions (\%) } & \multirow{2}{*}{$\begin{array}{l}\text { Unadjusted OR } \\
(95 \% \mathrm{Cl})\end{array}$} & \multirow[t]{2}{*}{$p$-value } & \multirow{2}{*}{$\begin{array}{l}\text { Adjusted OR } \\
(95 \% \mathrm{Cl})\end{array}$} & \multirow[t]{2}{*}{$p$-value } \\
\hline & Before $(n=180)$ & After $(n=180)$ & & & & \\
\hline Indication & $40(22.3)$ & $28(15.6)$ & $0.800(0.468-1.367)$ & 0.414 & $0.81 \mathrm{I}(0.456-1.445)$ & 0.478 \\
\hline Improper dose & 88 (48.9) & $67(37.2)$ & $1.613(1.060-2.456)$ & 0.026 & $1.879(1.173-3.011)$ & 0.009 \\
\hline
\end{tabular}

Note: adjusted for length of stay, wards, underlying disease, and type of infection.

Abbreviations: $\mathrm{Cl}$, confidence interval; $\mathrm{OR}$, odds ratio. 
after using the antimicrobial restriction system. The result of this study is in contrast with the results of Phaliphot et $\mathrm{al}^{7}$ who conducted a retrospective cohort research by recruiting patients from the critical care surgical ward at Maharaj Nakorn Chiang Mai Hospital between the year 2008 (before) and the years 2009-2011 (after) and found that the rate of P. aeruginosa resistance to imipenem increased by about $16 \%$ after using the antimicrobial restriction system $(p=0.011)$. In addition, Sistanizad et $\mathrm{al}^{8}$ studied the effect of an antimicrobial control program and found that the sensitivity of Pseudomonas spp. to imipenem had increased from $15.79 \%$ to $38.10 \%(p<0.01)$ after using the antimicrobial restriction system. However, the sensitivity of Enterobacteriaceae to imipenem was not found to change significantly during the study period. Pakyz et al, ${ }^{9}$ in a retrospective, longitudinal, multicenter analysis, showed that the incidence rates of carbapenem-resistant $P$. aeruginosa in hospitals that restricted carbapenems were significantly low for all 5 years compared with those that did not restrict $(p=0.01)$.

In this study, investigation of the appropriateness of prescribing demonstrated a statistically significant increase in carbapenem use (from $38.3 \%$ to $55.0 \%$ (odds ratio, 2.150; 95\% CI, 1.351-3.423; $p=0.001$ ); the amount of carbapenem in $\mathrm{DDD} / 1,000$ patient days increased from 616.71 to 638.20 $\mathrm{DDD} / 1,000$ bed days ( $p=0.611)$ without statistical significance and the expense for carbapenem use demonstrated a statistically significant decrease over a 5-month period (from $5,030.5$ to $3,202.9 \mathrm{THB} /$ person; $p=0.001)$. The results of this study were consistent with the findings of Ozkurt et $\mathrm{al}^{10}$

Table 7 Amount of carbapenem in dose prescribed per I,000 bed days (DDD/I,000 bed days)

\begin{tabular}{lllll}
\hline Drug & \multicolumn{2}{l}{$\begin{array}{l}\text { Mean DDD (g)/ } \\
\text { I,000 bed days }\end{array}$} & $\begin{array}{l}\text { \% difference } \\
\text { between before }\end{array}$ & $\begin{array}{l}\text { p-value } \\
\text { and after }\end{array}$ \\
\cline { 2 - 3 } & $\begin{array}{l}\text { Before } \\
(\mathbf{n}=\mathbf{1 8 0})\end{array}$ & $\begin{array}{l}\text { After } \\
(\mathbf{n}=\mathbf{1 8 0})\end{array}$ & & \\
\hline Carbapenem & $616.7 \mathrm{I}$ & 638.20 & +3.48 & $0.61 \mathrm{I}$ \\
Meropenem* & 597 & 642.05 & +7.54 & 0.972 \\
Ertapenem** & 761.86 & 609.07 & -20.05 & 0.220 \\
\hline
\end{tabular}

Notes: *Mapenem ${ }^{\circledast}$ (meropenem) from Siam Pharmaceutical, Bangkok, Thailand. **Invanz ${ }^{\circledR}$ (ertapenem) from Merck \& Co., Inc., Kenliworth, NJ, USA.

Abbreviation: DDD, defined daily dose. who found that the antimicrobial use decreased from $52.7 \%$ (before controlling) to $36.7 \%$ (after controlling; $p<0.001$ ). The appropriateness of prescribing was observed to increase from $55.5 \%$ to $66.4 \%(p<0.05)$. Similar to these, Allouch et $\mathrm{al}^{11}$ conducted a retrospective cohort study to compare antibiotic use, cost, and consumption before and after the application of the antibiotic restriction program; after using the antimicrobial restriction system, it was found that the rate of restricted antibiotic use had decreased by $11 \%(p<0.0001)$ and the ratio of the cost of restricted antibiotics had decreased by $9 \%(p=0.02)$.

In this study, in contrast to the observations made by Gyssens et al, ${ }^{12}$ it was found that after controlling, the amount of antimicrobial drug used (DDD/100 bed days) had increased from 59.8 to $72.6 \mathrm{~g}$; the appropriate prescribing was $53 \%$, the same as that in the study of Apisarnthanarak et $\mathrm{al}^{13}$ who obtained similar results after using education and an antibiotic-control program. Inappropriate use of antimicrobial drugs had decreased ( $42 \%$ vs $20 \% ; p<0.001)$, but the amount of carbapenem used had increased (2.93 vs 3.13; DDD/1,000 a day).

In addition, the evaluation results regarding the expense for antimicrobial drug use in this study are consistent with the results of a study by Ozkurt et $\mathrm{al}^{10}$ who found that after controlling the antimicrobial drug use, the total expenditure for the antimicrobial drugs had decreased by $18.5 \%$. The expense for the antimicrobial drug had reduced by 332,000 dollars per year. Similarly, Allouch et $\mathrm{al}^{11}$ found that the antimicrobial cost was saved by approximately US\$ 8,099 per month, and that the expenditure for all the antibiotics had decreased by $22.3 \%(p<0.001)$. In addition, Rattanaumpawan et $\mathrm{al}^{14}$ found that the antimicrobial drug outlay had reduced by US\$ 862,704 after using the drug use evaluation protocol.

The control and prevention of antimicrobial resistance rests on hospitals, and it is up to the hospital administration to realize its importance. Moreover, the policies adopted should be adequate and effective for the control and prevention of antimicrobial resistance in hospitals. For example, health care personnel who have sufficient knowledge should be employed, and the correct and adequate resources, such as separate rooms, body protectors, alcohol gels for hand

Table 8 Prescription drug expenses in average value of baht per patient

\begin{tabular}{|c|c|c|c|c|}
\hline \multirow[t]{2}{*}{ Drug } & \multicolumn{2}{|c|}{ Average value of baht per patient (min-max) } & \multirow{2}{*}{$\begin{array}{l}\% \text { difference between } \\
\text { before and after }\end{array}$} & \multirow[t]{2}{*}{$p$-value } \\
\hline & Before $(n=180)$ & After $(n=180)$ & & \\
\hline Carbapenem & $5,030.5(204.4-41,344.8)$ & $3,202.9(204.4-14,766.0)$ & -36.33 & 0.001 \\
\hline Meropenem & $4,320.4(204.4-35,560.4)$ & $3,023.8(204.4-12,262.2)$ & -30.01 & 0.014 \\
\hline Ertapenem & $9,888.7(1,968.8-41,344.8)$ & $4,558.5(984.4-\mid 4,766.0)$ & -53.90 & 0.005 \\
\hline
\end{tabular}


cleaning, and quality microbiology laboratories, should be present, and continuous development of the involved personnel should be followed. Thoroughly planned-out practices and dissemination practices should be followed. Additionally, the use of best practices is comprehensive, consistent, and continuous. Also, communication and coordination between the involved personnel is key to successful use of controlled antimicrobial agents even without ID specialists. ${ }^{3}$

\section{Limitations}

This study had its limitations: 1) The study had limited use of controlled antimicrobial agents. Thus, uncontrolled antimicrobial agents may have increased in use, leading to increased resistance to uncontrolled antimicrobial agents. 2) The 5-month study period may be too short to conclude the trend of using various drugs. The duration of study should be increased to 1 year (before and after antimicrobial control) in order to increase the number and variety of prescription samples included, so that the difference between the incidences of antimicrobial resistance can be detected. 3) As regards the amount of the drug (DDD) in some populations, such as patients with renal dysfunction and patients with low body weight, the value of DDD may have been underestimated.

\section{Conclusion}

The study results suggest that an antimicrobial restriction system can increase the appropriateness of prescribing antibiotics. The expenditure for carbapenem was decreased after using the antimicrobial restriction system when compared with before using the antimicrobial restriction system, even without ID consultation. However, the amount of carbapenem in the dose prescribed per 1,000 bed days was not found to have reduced after the use of the antimicrobial restriction system.

\section{Acknowledgment}

The authors thank Prof Dr Visanu Thamlikitkul for his comments on the patient records of this study.

\section{Disclosure}

The authors report no conflicts of interest in this work.

\section{References}

1. National Antimicrobial Resistance Surveillance, Thailand (NARST). Current status of national antimicrobial resistance among clinical isolates. [Internet]. 2010 [cited January 20, 2016]. Available from: http://www.thaidrugwatch.org/download/otherprint/2010_drug_system_report.pdf. Accessed January 20, 2016.

2. Dechsirilet S. Antibiotic Resistance and solution. [Internet]. 2012 [cited January 20, 2016]. Available from: http://old.hsri.or.th/sites/default/files/ hsri-forum-website.pdf. Accessed January 20, 2016.

3. Ogutlu A, Guclu E, Karabay O, Utku AC, Tuna N, Yahyaoglu M. Effects of Carbapenem consumption on the prevalence of Acinetobacter infection in intensive care unit patients. Ann Clin Microbiol Antimicrob. 2014;13(7):1-6.

4. Thamlikitkul V. The Control and Prevention Manual of Antimicrobial Resistance In The Hospitals. 1st ed. Bangkok: Faculty of medicine Mahidol University; 2015.

5. Hongchumphae $\mathrm{O}$. The analysis of carbapenem dose using defined daily dose in the overall use of hospital and wards. [Internet]. 2015 [cited January 22, 2016]. Available from: http://www.google.co.th/ url?url=http://thailand.digitaljournals.org/index.php/PHCDJ/article/ download/29308/28389. Accessed January 20, 2016.

6. WHO Collaborating Centre for Drug Statistics Methodology. ATC/ DDD Index [Internet]. 2015 [cited January 20, 2016]. Available from: http://www.whocc.no/atc_ddd_index/. Accessed January 20, 2016.

7. Phaliphot V, Chittawattanarat K, Ruengorn, C, Lucksiri A. Effects of antibiotic restriction program in critical care surgery patients at MaharajNakorn Chiang Mai hospital. Thai Pharm Health Sci J. 2015;10(2):59-66.

8. Sistanizad M, Kouchek M, Miri M, et al. Carbapenem restriction and its effect on bacterial resistance in an intensive care unit of a teaching hospital. Iran J Pharm Res. 2013;12(3):503-509.

9. Pakyz AL, Oinonen M, Polk RE. Relationship of carbapenem restriction in 22 university teaching hospitals to carbapenem use and carbapenemresistant Pseudomonas aeruginosa. Antimicrob Agents Chemother. 2009;53(5):1983-1986.

10. Ozkurt Z, Erol S, Kadanali A, Ertek M, Ozden K, Tasyaran MA. Changes in antibiotic use, cost and consumption after an antibiotic restriction policy applied by infectious disease specialists. Jpn J Infect Dis. 2005;58(6):338-343.

11. Allouch A, Sabbah H, Hassan S, Sabbah S, Droubi N, Sabbah I. Antibiotic use, cost and consumption in tertiary hospitals in Lebanon: a comparative study before and after an implementation of antibioticrestriction program (ARP). BJMMR. 2016;12(3):1-15.

12. Gyssens IC, Blok WL, Van den Broek PJ, HeksterYA, Van der Meer JW. Implementation of an educational program and an antibiotic order form to optimize quality of antimicrobial drug use in a department of internal medicine. Eur J Clin Microbiol Infect Dis. 1997;16(12):904-912.

13. Apisarnthanarak A, Danchaivijitr S, Khawcharoenporn T, et al; Thammasart University Antibiotic Management Team. Effectiveness of education and an antibiotic-control program in a tertiary care hospital in Thailand. Clin Infect Dis. 2006;42(6):768-775.

14. Rattanaumpawan P, Sutha P, Thamlikitkul V. Effectiveness of drug use evaluation and antibiotic authorization on patients' clinical outcomes, antibiotic consumption and antibiotic expenditures. Am J Infect Control. 2010;38(1):38-43.
International Journal of General Medicine

Publish your work in this journal

The International Journal of General Medicine is an international, peer-reviewed open-access journal that focuses on general and internal medicine, pathogenesis, epidemiology, diagnosis, monitoring and treatment protocols. The journal is characterized by the rapid reporting of reviews, original research and clinical studies across all disease areas.

\section{Dovepress}

The manuscript management system is completely online and includes a very quick and fair peer-review system, which is all easy to use. Visit http://www.dovepress.com/testimonials.php to read real quotes from published authors. 